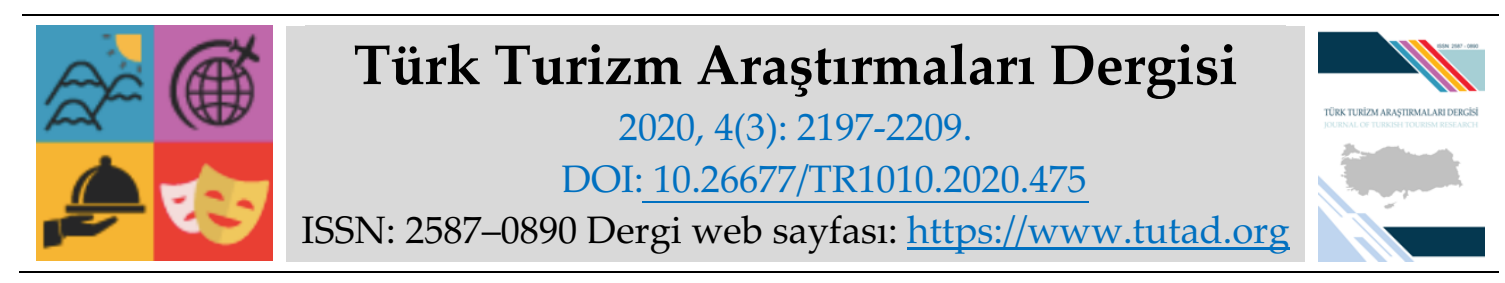

ARASTIRMA MAKALESI

\title{
Açık Alan Rekreasyon Aktivitelerine Katılmayı Motive Eden Faktörlere Yönelik Ölçek Geliştirme Çalışması
}

Dr. Öğr. Üyesi Ebru GÖZEN, Akdeniz Üniversitesi, Manavgat Turizm Fakültesi, Antalya, e-posta: ebrugozen@akdeniz.edu.tr ORCID: https://orcid.org/0000-0002-3476-5023

Öz

Çalışmanın temel amacı, öncelikle 'rekreasyon aktivitelerine katılım motivasyon ölçeği' geliştirmektir. Literatür taraması sonucu ölçek geliştirilmiştir. Veriler, 2019 yılında Antalya destinasyonunda spor kulüplerine üye olan ve olmayan amatör rekreasyon katılımcılarına uygulanan anket ile toplanmıştır. Ölçek ile ilgili açımlayıcı ve doğrulayıcı analizler gerçekleştirilmiştir. Faktör analizi sonucuna göre, toplam varyansın \%60,86'sını açıklayan beş boyutlu (başarı odaklılık, zorluklara meydan okuma, risk alma, bireysellik ve yenilik) ölçek elde edilmiştir. KMO değerleri incelendiğinde, 0,50'nin altına düşen bir değer olmadığından dolayı boyutların KMO değerleri kabul edilebilir düzeydedir. Boyutlardaki ifadelerin faktör yüklerine bakıldığında ise, en düşük olan değer $0,485^{\prime}$ dir ve 0,40 altında herhangi bir değer olmaması, ifadelerin boyutlar için uygun olduğunu göstermektedir. CA değerleri ise, 0,80 üstüdür ve bundan dolayı boyutlar güvenilirdir ve iç tutarlığa sahiptir. Faktör analizi sonrasında yapısal eşitlik modeli aracılığıyla DFA analizi yapılmıştır. Sonuçlara göre modelin uyum iyiliği yeterlidir.

Anahtar Kelimeler: Motivasyon, Açık Alan Rekreasyon Aktiviteleri, Ölçek Geliştirme.

Makale Gönderme Tarihi: 21.03.2020

Makale Kabul Tarihi: 03.07.2020

\section{Önerilen Atıf:}

Gözen, E. (2020). Açık Alan Rekreasyon Aktivitelerine Katılmayı Motive Eden Faktörlere Yönelik Ölçek Geliştirme Çalışması, Türk Turizm Araştırmaları Dergisi, 4(3): 2197-2209.

(c) 2020 Türk Turizm Araştırmaları Dergisi. 


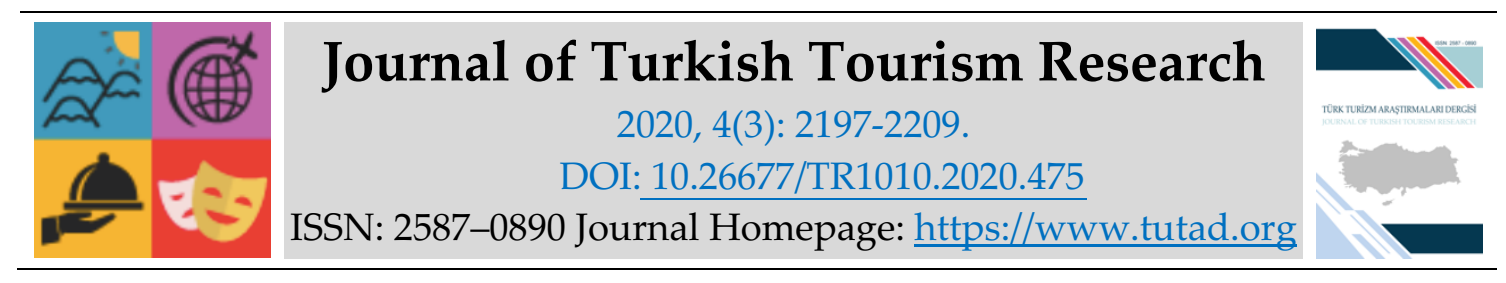

\title{
$\underline{\text { RESEARCH PAPER }}$
}

\section{A Scale Development Study for Factors Motivating Participation in Outdoor Recreation Activities}

Assistant Prof. Dr. Ebru GÖZEN, Akdeniz University, Manavgat Faculty of Tourism, Antalya, e-mail: ebrugozen@akdeniz.edu.tr

ORCID: https://orcid.org/0000-0002-3476-5023

\begin{abstract}
The main purpose of the study is to develop a " scale for determine factors motivating participation in recreation activities". The scale was developed as a result of the literature review. The data were collected by a questionnaire applied to amateur recreation participants who were members and unmember of sports clubs in Antalya destination in 2019. Exploratory and confirmatory analyzes related to the scale were performed. According to the result of the factor analysis, a five-dimensional scale (success-oriented, challenge, risk-taking, individuality and innovation) was obtained, which explained $60.86 \%$ of the total variance. When the KMO values are examined, the KMO values of the dimensions are at an acceptable level since there is no value below 0.50 . When factor loads of the items in the dimensions are examined, the lowest value is 0.448 and no value below 0.40 indicates that the expressions are suitable for the dimensions. CA values are above 0.80 , so the dimensions are reliable and have internal consistency. After factor analysis, DFA analysis was done through structural equation model. According to the results, the goodness of fit of the model is sufficient.
\end{abstract}

Keywords: Motivation, Outdoor Recreation Activities, Scale Development.

Received: 21.03 .2020

Accepted: 03.07.2020

\section{Suggested Citation:}

Gözen, E. (2020). A Scale Development Study for Factors Motivating Participation in Outdoor Recreation Activities, Journal of Turkish Tourism Research, 4(3): 2197-2209.

(C) 2020 Türk Turizm Araştırmaları Dergisi. 


\section{Gíriş}

Rekreasyon, boş zamanlarda yapılan ve bu yapılan faaliyetten dolayı oluşan memnuniyetle motive olunmuş bir olaydır (Brightbill, 1961). Douglas (1980) rekreasyon kavramını hem çocukların hem de yetişkinlerin boş zaman aktiviteleri olarak ifade etmiştir. Jubenville (1976) ise rekreasyonu yeniden yaratma, bireyin doğrudan kendisine getirdiği kişisel zevk ve memnuniyet nedeniyle, tercih ettiği bir şekilde seçtiği herhangi bir deneyim veya faaliyet biçimi olarak tanımlamıştır.

Açık alan rekreasyonu, açık havada gerçekleşen ve insanların doğal çevre ile etkileşimlerini kucaklayan serbest zaman aktivitesidir (Plummer, 2009). Doğal dünya ile yakın temas halinde olan aktiviteler günümüzde popülerlik kazanmaktadır. Her yıl daha fazla insan kayak, tırmanma, kano, paraşütle atlama, tüplü dalış, kros koşuları gibi açı alan rekreasyonlarına katılmaktadır (Priest ve Gass, 1997). Çünkü açık alan rekreasyonunun katılımcılar üzerinde birçok olumlu sonucu bulunmaktadır. Bunlardan bazıları; psikolojik ve sosyal refahı iyileştirmek, sağlıklı hissetmek, risk almayı ve risk yönetimini öğrenmek, bilişsel becerileri geliştirmek, kendisinin ve başkalarının sorumluluğunu almak, rahatlamak veya doğayı derinden yaşamak (Ardahan ve Lapa, 2011; Berman vd., 2008; İbrahim ve Cordes, 2002).

Rekreasyon faaliyetlerine katılmayı engelleyen veya motive birçok faktör bulunmaktadır. Bu faktörler; sezonluk engeller, finansal kaynaklar ve rekreasyon alanlarının ulaşılabilir olması, cinsiyet ve sosyal sınırlama, fiziksel kaynaklar ve moda olmak üzere dört başlık altında toplanabilir (Hall vd., 2006). İnsanların yaşadığı fiziksel çevre sadece katılımcı olmasını değil, çoğu zaman katılacağı rekreasyon faaliyetinin türünü de etkilemektedir (Hall vd., 2006). Sosyal politikalar, emeklilikte geçirilen süre, etnik yapı, evde eğitim imkanı ve fırsatların algılanması da rekreasyon aktivitelerine katılımı etkileyen bazı faktörlerdir (Demir ve Demir, 2006). Fizyolojik, alanların durumu, ekonomik, organizasyonel ve ruhsal faktörler de rekreasyon aktivitelerine katılımı etkileyebilmektedir (Yayla ve Çetiner, 2019). Rekreasyon faaliyetlerine katılımı etkileyen diğer bir unsur bireylerin ekonomik düzeyidir (Torkildsen, 1999). Çalışan kadınlar, çalışan erkeklere göre daha az boş zamana sahiptirler. Kadınlar çalışma dışı zamanlarının büyük bir kısmını ev işleriyle uğraşarak geçirmektedirler. Ayrıca çocuk sahibi kadınlar çalışma saatleri ve ev işlerine ayırdıkları zamandan geriye kalan saatlerinin büyük bir kısmını da çocuklarıyla ilgilenerek geçirmektedirler. Bu durumun en büyük sebebi toplumda bu görevlerin kadının yükümlülüğü olduğuna dair bir görüşün hakim olmasıdır. Cinsiyet faktörünün dişında rekreasyon faaliyetlerine katılımı etkileyen sosyal faktörler de mevcuttur (Broadhurst, 2001).

Açık alan rekreasyonu aynı zamanda bazı yüksek risklere sahiptir. Bu riskler, gerçekleştirilen açık alan rekreasyonu türüne göre değişmektedir; örneğin paraşütle atlama, yamaç paraşütü ve dağcllık yaparken insanlar yerçekimi kuvvetinden dolayı karıncalanma veya uyuşma hissiyle karşılaşabilir. Benzer şekilde sörfçüler, dalgıçlar, kanocular ve kayakçlların yaptığı gibi suyun gücüyle mücadele etmek veya kayak dağcılığı ve dağ bisikleti gibi doğanın zorlu arazi şartlarıyla başa çıkmak çok kolay değildir. Bu zorluk faktörlerine rağmen bireyler bu tür açı alan rekreasyon faaliyetlerine katılmaktadır. Bundan dolayı bireylerin açık alan rekreasyon faaliyetlerine katılmaları için nasıl motive oldukları ile ilgili bazı unsurlar belirlenmiştir: akış (Csikszentmihalyi, 1990); duyum arayışı (Zuckerman, 1994), öz yeterlik (Llewellyn ve Sanchez, 2008) ve içsel motivasyon (Asci vd, 2007; Deci ve Ryan, 2000). Bazı çalışmalar da açık alan rekreasyon aktivitelerine katılımın motivasyona bağlı olarak belirlenebileceğini ifade etmektedir (Schüler vd., 2014).

Armutcu (2018), kamu ve özel kurumlar tarafından yaptırılan park ve rekreasyonel alanlarının vatandaşlar tarafından kullanımını etkileyen faktörleri belirlemiştir. Sonuçlara göre, katılımcıların fiziksel aktivite amaçlı park ve rekreasyon alanlarının kullanım engellerinin; 
medeni durum, cinsiyet, eğitim durumu, yaş, spor yapma sıklıklarına ve geliş nedenlerine göre anlamlı farklılıklar gösterdiği belirlenmiştir. Akademisyenler üzerine gerçekleştirmiş olduğu çalışmada Başarangil (2018), akademisyenlerin boş zaman aktivitelerine katılımının iş tatmini üzerinde etkisi bulunmadığı ortaya çıkmıştır. Mansuroğlu ve Dağ (2019), eğitim-öğrenim dönemlerinin belli bir bölümünde rekreasyon ile ilgili dersler alan, Akdeniz Üniversitesi Mimarlık Fakültesi Peyzaj Mimarlığı Bölümü lisans öğrencilerinin dış mekan rekreasyon aktivitelerine yaklaşımlarının belirlenmesi amacıyla çalışma gerçekleştirmiştir. Yazarlar, öğrencilerin en fazla katıldıkları etkinliklerin yürümek, bisiklet sürmek ve yüzmek olduğu, rekreasyon aktivitelerine katılamama nedenlerinin başında ise, zaman yetersizliğinin geldiği sonucuna ulaşmıştır. Bundan dolayı çalışmanın temel amacı öncelikle 'rekreasyon aktivitelerine katılım motivasyon ölçeği' geliştirmektir.

\section{MCCLELLAND MOTIVASYON (IHTTIYAÇ) TEORISİ ve REKREASYON AKTIVITELERI}

McClelland'ın İnsan Motivasyon Teorisi aynı zamanda "üç sosyal güdü" ve "Edinilmiş İhtiyaç Teorisi" olarak da isimlendirilmektedir. McClelland (1961, 1975, 1985) tarafından geliştirilen ihtiyaç teorisi, bireylerin üç temel ihtiyaç faktörü tarafından motive edildiğini ifade etmektedir: başarı ihtiyacı, güç ihtiyacı vebağlılık ihtiyacı. McClelland'a (1987) göre, herkes bazı ihtiyaçlardan güçlü ve bazı ihtiyaçlardan daha az motive olmaktadır. Başarıya duyulan ihtiyaç önemli başarı, kontrol, yüksek standartlar ve becerilerin kazanılması için insanları motive etmektedir. McClelland (1961) başarmaya olan ihtiyacı, bazı mükemmellik standartlarıyla rekabette elde edilen başarı olarak tanımlamıştır. Yani, bazı bireylerin amacı, bazı mükemmellik standartlarıyla rekabette başarılı olmaktır. Bundan dolayı başarıya olan ihtiyaç, diğer bir ifadeyle 'başarı odaklılık' insanları daha riskli olan açık alan rekreasyonaktivitelerine itebilir.

Başarı ihtiyacı; biliş, duygular, davranışlar ve çevre arasındaki ilişkilerin ve etkileşimlerin bir sonucudur.Bu nedenle, başarıya ihtiyaç duyan insan, hedeflere meydan okumaya istekli ve gerçekçi olan kişi olarak bilinmektedir (Daft, 2008). Bu ihtiyaç riskin dahil olduğu yeni ve belirsiz durumlarla ilgilidir.Dolayısıyla açık alan rekreasyon aktivitelerinde paraşütle atlama, rafting gibi riskin dahil olduğu aktivitelere katılmanın altında insanların 'zorluklara meydan okuması' ve başarı ihtiyaçlarını tatmin etme istekleri yatabilir.Başarmaya duyulan ihtiyaç, cesaret ve devamlılık gerektiren yenilikçi eylemlerin üstlenilmesini düzenlemektedir (McClelland vd., 1989). Düşük başarıya ihtiyaç duyan insanlar, başarısızlık riskinden kaçınmak istedikleri için basit hedefler seçebilirken, başarı ihtiyacı yüksek olan bireyler orta derecede zor hedefleri seçebilirler (McClelland, 1961). Bundan dolayı açık alan rekreasyon aktivitelerine katılmada 'risk alma' faktörü insanları motive eden faktörlerden biri olarak karşımıza çıkmaktadır. Başarıya duyulan ihtiyaç; öz yeterlik ya da vicdan sahibi olma gibi diğer motive edici özellikler ile olumlu yönde ilişkilidir (Chen vd., 2000). McClelland'ın (1985) başarıya duyulan ihtiyaç kavramı, bir kişinin belirlenmiş standartlara göre üstünlüğünü açıklamaktadır. Bireylerin başarma ihtiyaçları, başkalarının durumlarına bakılmaksızın, kendi amaçlarını gerçekleştirebildiklerinde karşılanmaktadır (Yamaguchi, 2003). Başarısı yüksek olanlar tesadüfen başarıya ulaşmaktan hoşlanmazlar ve sonucu olasılığa bırakmak yerine, başarıları veya başarısızlıkları için kişisel olarak tanımlanabilir kaynaklar aramaktadırlar (Robbins, 2003).Bu durum açık alan rekreasyon aktivitelerine bireysel olarak katılanlar ile ilgilidir. Başka bir ifadeyle 'bireysellik' faktörü kapsamında başkalarına bakılmaksızın kişisel olarak tanımlanan kaynaklar insanları açık alan rekreasyon aktivitelerine katılmaya motive edebilir.Başarma düzeyi yüksek olan bireyler, çabalarının tanımlanabilir sonuçlarına bağlı olarak da sevinç ya da üzüntü yaşamalıdır (McClellandve Koestner, 1992). 
Başarı ihtiyacı, bireylerin zor bir durumda kötümser mi yoksa iyimser mi düşündüklerini belirlemekte ve insanların amaçlarına ulaşmak için kendilerini motive etme şeklini etkilemektedir. Başarı elde etmek için daha yüksek motivasyona sahip olanlar, yaşamın tadını çıkarmakta ve yaşamın kontrolde olduğunu hissetmektedir (Singh, 2007). Büyük başarılara ihtiyaç duyan insanlar, zorluklar veya potansiyel başarısızlıklar(risk alma)karşısında çabalarını ve devamlılıklarını (yenilik) arttırmaktadır (Bipp ve Dam, 2014). Böylelikle, başarıya ulaşma konusunda yüksek seviyelerde motivasyon sürdürülmekte (başarı odaklılık) ve beceri gelişimi arttırılmaktadır (Lussier ve Achua, 2007). Başarma ihtiyacı yüksek olan bireyler, zorlu hedefleri gerçekleştirmekten (zorluklara meydan okuma) zevk almakta ve zor hedefleri kendilerini daha iyi hale getirmek için fırsatlar olarak görmektedirler. Başarma ihtiyacı yüksek olan bireyler, becerilerini geliştirmek ve başarıyı kişisel bir sorumluluk (bireysellik) olarak görmek için çaba harcamaktadır (Elliot ve Church, 1997). Lussierve Achua (2007) güç ihtiyacını, başkalarını etkilemek ve otorite kurmak için bilinçsiz bir endişe olarak tanımlamıştır. Bu, başkalarının kendisi tarafından gösterilecek olan davranışlarda bulunma arzusu olarak tanımlanmaktadır. Daft (2008), güç ihtiyacını başkalarını kontrol etme veya etkileme, başkaları üzerinde yetki sahibi olma ve başkalarından sorumlu olma arzusu olarak tanımlamıştır. Birey ayrıca diğerleri üzerinde etkili olmak için etkili bir performans yaratma eğilimindedir. Bu durumda, birey hedefe ulaşmak ve her durumu mükemmellik yolunda yapmak için başkalarıyla rekabet etmek ister McClelland (1961). Başka bir ifadeyle 'bireysel' 'risk alarak' 'zorluklara meydan okuyup' 'başarı elde etmek' için güce ihtiyaç duyulmaktadır. Bunu yaparken de devamlılık ve etkileme için 'yenilik' gerekmektedir. Güç ihtiyacı yüksek olanlar rekabetçi ve statü odaklı durumlarda olmayı tercih etmektedir (Veroff, 1992). Dolayısıyla insanlar açık alan rekreasyon aktivitelerine katılmak için güç ihtiyacı kapsamındaki 'bireysel', 'risk alarak', 'zorluklara meydan okuma', 'başarı elde etme' ve 'yenilik' faktörleri tarafından motive edilebilir. Bağlılık ihtiyacı başkalarıyla arkadaşça ve yakın ilişkiler kurma arzusunu ifade etmektedir (McClelland, 1985; Robbins, 2003). Daft (2008) bağlılık ihtiyacını yakın kişisel ilişkiler kurma, çatışmadan kaçınma ve sıcak dostluk kurma arzusu olarak tanımlamıştır. Bağlılık ihtiyacı yüksek olanlar, başkalarıyla etkileşime girme yolunda uzun zaman harcama eğilimindedir (McClellandveKoestner, 1992). Ayrıca, güçlü bir bağlılığa ihtiyaç duyanlar, başkalarıyla karşılıklı bağımlılık ve işbirliğinin çok önemli olduğu takım etkinliklerine ilgi duymaktadır (Yamaguchi, 2003). Bağlılık ihtiyacı olan kişiler, sosyal kabul edilme, arkadaşlık ve kişilerarası ilişkiler elde etme arayışındadır. Bu açıdan, birey toplumda daha fazla arkadaş edinmek için başkalarıyla ilişki kurma eğilimindedir (Lussier veAchua, 2007). Bağlılık ihtiyacı kapsamında sosyal kabul edilme, arkadaşlıklar ve ilişkiler kurmak amacıyla insanlar açık alan rekreasyon aktivitelerine katılmaya motive olabilir.

Boyatzis (2000), McClelland'ınmotivasyon (ihtiyaç) teorisindeki baskın olan üç motive eden unsur kapsamında insanların özelliklerini belirlemiştir. Tablo 1'de bu unsurlar çalışma kapsamındaki faktörlerin karşılığı olacak şekilde verilmiştir.

McClelland'ın motivasyon (ihtiyaç) teorisinin en önemli özelliği farklı insanların farklı kişilikleri ve dolayısıyla farklı motivasyonlara sahip olduğunu dikkate almasıdır. Her insanın rolü bazı durumlar ve kişisel özellikler nedeniyle değişebilir. Bunun yanı sıra, herkesin farklı durumlarda güçlü ve zayıf yanları vardır (Swenson, 2000). Gerçekleşen çalışmanın ikinci amacı, açık alan rekreasyon aktivitelerine katılanların demografik özelliklerinin tercih ettikleri rekreasyon aktivitelerinde farklılaşma oluşturup oluşturmadığını belirlemek olduğundan dolayı McClelland'ın motivasyon (ihtiyaç) teorisi çalışma için seçilmiştir. 
Tablo 1. Baskın Motivatörler ve Ölçek Faktör Karşılıkları

\begin{tabular}{|c|c|c|}
\hline Motivatör & İnsan Özelliği & Ölçek Faktör Karşılığg \\
\hline Başarı & $\begin{array}{l}\text {-Zorlu hedefler koyma ve gerçekleştirme konusunda } \\
\text { güçlü bir ihtiyacı vardır. } \\
\text {-Hedeflerine ulaşmak için hesaplanmış riskler alır. } \\
\text {-İlerlemeleri ve başarıları hakkında düzenli } \\
\text { geribildirim almayı sever. } \\
\text {-Genellikle yalnız çalışmayı sever. }\end{array}$ & $\begin{array}{l}\text {-Zorluklara meydan } \\
\text { okuma } \\
\text {-Risk alma } \\
\text {-Başarı odaklılık, } \\
\text { yenilik } \\
\text {-Bireysellik }\end{array}$ \\
\hline Bağlılık & $\begin{array}{l}\text {-Gruba ait olmak ister. } \\
\text {-Rekabet üzerinde işbirliğini destekler. } \\
\text {-Yüksek risk veya belirsizliği sevmez. }\end{array}$ & $\begin{array}{l}\text {-Bireysellik } \\
\text {-Başarı odaklılık } \\
\text {-Risk alma, yenilik }\end{array}$ \\
\hline Güç & $\begin{array}{l}\text { Başkalarını kontrol etmek ve etkilemek ister } \\
\text { Tartışmaları kazanmayı sever. } \\
\text { Rekabeti ve kazanmayı sever. }\end{array}$ & $\begin{array}{l}\text {-Bireysellik } \\
\text {-Başarı odaklılık } \\
\text {-Risk alma }\end{array}$ \\
\hline
\end{tabular}

Kaynak: Boyatzis'in (2000) çalı̧̧masından uyarlanmıştır.

\section{YÖNTEM}

Çalışmanın temel amacı 'rekreasyon aktivitelerine katılım motivasyon ölçeği' geliştirmektir. Bu amaçla, beşli Likert tipi modele uygun (Köklü, 1995) şekilde tasarlanarak veriler toplanmıştır. Toplanan verilerle açımlayıcı ve doğrulayıcı faktör analizleri gerçekleştirilmiştir. Çalışma grubu ve ölçek geliştirme süreci aşağıda detaylı olarak verilmiştir.

\section{Çalışma Grubu}

Anket formu Antalya destinasyonunda spor kulüplerine üye olan ve olmayan amatör rekreasyon katılımclarına Ekim 2019 tarihinde uygulanmıştır. Spor kulüplerine üye olmayan rekreasyon katılımcı sayısı net olarak bilinememesinden dolayı örneklem sayısında Yazıcığlu ve Erdoğan'ın (2004) sosyal bilimlerde örneklem büyüklükleri hesaplaması dikkate alınmıştır. Bu kapsamda toplam 394 adet anket ile veri elde edilmesi çalışmanın gerçekleştirilmesi için yeterli görülmüştür. Katılımcların \% 60,2'si erkek ve \% 39,8'i kadındır. Medeni durum olarak katılımcların \% 35,5'i evli ve \% 64,5'i bekardır. Katılımcıların \% 42,6'sı lisans mezunuyken \% 28,2'si ilköğretim mezunudur. Yaş durumu incelendiğinde ise katılımcıların \% 27,4'ünün '21-25' yaş grubunda ve $\%$ 25'4'ünün '32-40' yaş grubunda olduğu belirlenmiştir. Katılımcıların \% 30,5'i '2000 ve altı' gelir grubundayken \% 20,8'i '5001 ve üstü' grubunda yer almaktadır. Katılımcıların açı alan rekreasyon aktivitelerine katılım sıklıkları incelendiğinde ise katılımcıların \%35,3'ü ayda bir defa, $\%$ 25,9'u haftada bir defa, \% 24,6'sı 15 günde bir defa ve \% 14,2'sı ayda birden az açık alan rekreasyon aktivitelerine katılmaktadır.

\section{Ölçek Geliştirme Süreci}

Başarıya ilişkin ölçümler, genel başarı ihtiyacını ve özel başarı ihtiyacını belirlemek için ölçekleri kapsamaktadır. Genel olarak başarıya duyulan ihtiyaç ölçekleri nispeten daha az çalışılmış olmasından dolayı, bu konuda geniş bir bağlamda insan davranışını belirlemek için kullanılan Başarı Motivasyon Envanteri gibi ölçekler mevcuttur (Schülervd, 2014). Özel başarı ihtiyacının ölçülmesi iş (Amabile vd., 1994), spor (Conroy vd., 2003) veya eğitim (Elliot ve Murayama, 2008) gibi çeşitli konulara odaklanmıştır. Heyecan ve macera arayan ölçeği, doğal ortamlardaki macera 
ve risk aramasını ölçmekte ve bu ölçek rekreasyonel aktivitedeki başarılarla ilgili ifadeleri kapsamamaktadır (Zuckerman, 1994). Vahşi doğada yenilik arama ölçeği ise, vahşi doğada merak ve yenilik aramayı ölçmektedir. Bu ölçek de başarılarla bağlantılı değildir (Prochniak, 2014). Prochniak (2016) üniversite öğrencilerinde elde ettiği veriler ile açık alan rekreasyon aktivitelerine yönelik başarma ihtiyacı (motivasyon) ölçeği geliştirmiştir. Bundan dolayı çalışmada kullanılan ölçüm aracı Prochniak'ın (2016) üniversite öğrencilerine yönelik geliştirdiği başarma ihtiyacı (motivasyon) ölçeği temel alınarak literatür taraması sonrası oluşturulmuştur, çünkü çalışmada dört adet geliştirilmiş olan motivasyon ve ihtiyaç teorisi ölçeklerinin kıyaslaması ve analizleri gerçekleştirilmiştir (Prochniak, 2016).

Ölçüm aracı oluşturma Bozdoğan ve Öztürk'ün (2008) ölçek geliştirme süreci temelinde gerçekleştirilmiştir. Bozdoğan ve Öztürk'ün (2008) ölçek geliştirme süreci dört aşamadan oluşmaktadır. Bu aşamalar; madde havuzu oluşturma, uzman görüşü, geçerlilik ve güvenirlik bölümleridir. Literatür taranarak madde havuzu oluşturulmuştur. Madde havuzu oluşturulurken kullanılan çalışmaların detayları Tablo 2' de verilmiştir.

Tablo 2. Madde Havuzu Yararlanılan Kaynaklar

\begin{tabular}{|l|l|}
\hline Yazar(lar) & Ölçek \\
\hline McClelland (1985) & Human Motivation \\
\hline McClelland ve Koestner (1992) & The Achievement Motive \\
\hline Schüler ve Prochaska (2000) & Job-related Achievement Motivation Test \\
\hline Conroy ve ark. (2003) & Achievement Goals Questionnaire \\
\hline Mittelstaedt ve Jones (2008) & Outdoor Recreation Self- Efficacy Sclae \\
\hline Prochniak (2014) & Wilderness Novelty Seeking Scale \\
\hline Prochniak (2016) & Need for Achievement in Outdoor Recreation Scale \\
\hline
\end{tabular}

Madde havuzundan toplam 89 ifade seçilmiştir. Oluşturulan maddeler uzman görüşüne (2 turizm akademisyeni, 2 açık alan rekreasyon uzmanı ve 2 psikolog) sunulmuştur. Uzmanlardan maddelerin ölçek için uygunluğuna ilişkin cevaplarını 3'lü derecelendirme ölçeği (1: Kaldırılmalı, 2: Revize edilmeli, 3: Kalmalı) üzerinde belirtmeleri istenmiştir. Uzmanların açıklama yapmalarına olanak vermek için her bir maddenin altına bir boşluk bırakılmış ve uzmanlara gerektiğinde maddeler üzerinde de düzeltme yapabilecekleri belirtilmiştir. Uzmanlardan gelen formlar toplandıktan sonra, tüm cevaplar tek bir formda birleştirilmiştir. Uzman görüşü sonrası, bazı ifadelerin çıkarılması bazılarının yeniden düzenlenmesi sonucunda 58 ifade ile anket formu oluşturulmuştur. Ölçek beşli Likert olarak (1: Hiç uygun değil; 5: Tamamen uygun) hazırlanmiştır.

\section{BULGULAR}

Katılımclara katılmayı sıklıkla tercih ettikleri açık alan rekreasyon aktivitesi ile ilgili yöneltilen sorunun sonuçlarına göre, katılımcıların en çok katılmayı tercih ettikleri ilk altı açık alan rekreasyon aktivitesi sırasıyla; kampçılık ( $\mathrm{f}=182)$, dağ-kaya tırmanışı ( $\mathrm{f}=131)$, balıkçılık ( $\mathrm{f}=93)$, rafting $(\mathrm{f}=78)$, dağ bisikleti $(\mathrm{f}=67)$ ve at binmedir $(\mathrm{f}=54)$. Geri kalan aktivitelerin tercih siralaması ise; kayak ( $\mathrm{f}=52)$, tüplü dalış ( $\mathrm{f}=51)$, mağaracılık $(\mathrm{f}=37)$, paraşütle atlama (36), orienteering (yön bulma) ( $\mathrm{f}=35)$, yamaç paraşütü $(\mathrm{f}=34)$, bungyjumping $(\mathrm{f}=31)$, trekking $(\mathrm{f}=29)$, kano $(\mathrm{f}=28)$, kay kaypaten $(\mathrm{f}=26)$, sörf $(\mathrm{f}=22)$, snowboard $(\mathrm{f}=19)$, zipline $(\mathrm{f}=17)$, yelkencilik $(\mathrm{f}=15)$, su kayağ $(\mathrm{f}=15)$, yüzme ( $\mathrm{f}=14)$, yürüyüş $(\mathrm{f}=10)$ ve bisiklet sürme $(\mathrm{f}=4)$ şeklindedir. 
Elde edilen verilerin faktör analizine uygunluğunu belirlemek amacıyla tüm ifadelerin Skewness (Çarpıklık) ve Kurtosis (Basıklık) değerlerine bakılmıştır. Elde edilen değerler [(-1,5) ve $(1,5)]$ arasında olduğu için verilerin normal dağıldığı kabul edilmiştir (Şencan, 2005). Verilerin normal dağıldığı sonucuna ulaştıktan sonra ölçek geçerlilik ve güvenirliliği ilk aşaması olan KMO (Kaiser-Meyer-Olkin) ve Bartlett's Test of Sphericity gerçekleştirilmiştir. Tavşancll'a (2010) göre KMO değerinin 1'e yaklaştıkça mükemmel ve 0,50'nin altına düşünce ise kabul edilmez olduğu varsayılmaktadır. Çalışmada KMO değeri 0,905 olarak hesaplanmıştır. KMO değerinin faktör analizinde 1'e yakın olması çalışmadaki örneklem büyüklüğünün faktör analizi için uygun olduğunu desteklemektedir. Barlett's değeri ise anlamlı bulunmuştur $(p<0,01)$. Bu nedenle verilerin çok değişkenli normal dağılımdan geldiği kabul edilmiştir.

Faktör analizi ölçekteki toplam 58 ifade ile varimax dik döndürme yöntemiyle gerçekleştirilmiştir. Toplam 58 maddeyi içeren faktör analizi sonucunda, özdeğeri 0,30'un altında kalan (Nunnally, 1970), faktör yükü 0,40' ın altında olan (Zeller ve Karmines, 1978) ve birden çok faktör altında yüksek değer verdiği belirlenen 22 madde faktör analizinden çıkarılmış ve analiz sonucu beş boyut elde edilmiştir. Elde edilen boyutlardaki ifadeler kendi aralarında korelasyon analizine tabi tutulmuş ve yüksek korelasyona sahip herhangi bir ifade belirlenmemiştir. Geriye kalan 36 madde ile yapılan faktör analizi sonucuna göre toplam varyansın \%60,859'unu açılayan beş boyutlu ölçek elde edilmiştir. Boyutlar; motivasyon (ihtiyaç) teorisi de dikkate alınarak başarı odaklılık (BO), zorluklara meydan okuma (ZMO), risk alma (RA), bireysellik (BB) ve yenilik (YB) olarak isimlendirilmiştir. Bu boyutlar ile ilgili bulunan istatistiki değerler Tablo 3'de verilmiştir.

Tablo 3. Ölçek Boyutlarının Faktör Analizi Değerleri

\begin{tabular}{|c|c|c|c|c|c|}
\hline Faktör & İfade \# & Varyans Açılama \% & CA & KMO & $\begin{array}{c}\text { Min ve Max Faktör } \\
\text { Yükleri }\end{array}$ \\
\hline BO & 10 & 40,96 & 0,831 & 0,863 & $0,485-0,781$ \\
\hline ZMO & 9 & 47,69 & 0,861 & 0,881 & $0,618-0,773$ \\
\hline RA & 6 & 58,69 & 0,856 & 0,865 & $0,657-0,831$ \\
\hline BB & 5 & 56,35 & 0,806 & 0,797 & $0,682-0,850$ \\
\hline YB & 5 & 50,51 & 0,800 & 0,815 & $0,601-0,787$ \\
\hline
\end{tabular}

Tablo 3'de KMO değerleri incelendiğinde, 0,50'nin altına düşen bir değer olmadığından dolayı boyutların KMO değerleri kabul edilebilir düzeydedir. Boyutlardaki ifadelerin faktör yüklerine bakıldığında ise, en düşük olan değer 0,485'dir ve 0,40 altında herhangi bir değer olmaması, ifadelerin boyutlar için uygun olduğunu göstermektedir. CA değerleri ise, 0,80 üstüdür ve bundan dolayı boyutlar güvenilirdir ve iç tutarlığa sahiptir (Tavşancıl, 2010). Faktör analizi sonrasında yapısal eşitlik modeli aracılığıyla DFA analizi yapılmıştır. Tablo 4'de uyum iyiliği indeks değerleri (DFA sonuçları) verilmiştir.

GFI değeri 0 ile 1 arasında değişir. GFI'nın 0,90'ı aşması iyi bir model göstergesi olarak kabul edilmektedir. Bu, gözlenen değişkenler arasında yeterince kovaryansın hesaplandığı anlamına gelmektedir (Ventura, 2011). Çalışmada bu değer GFI=0,91 olarak bulunmuştur. NFI varsayılan modelin sıfır hipoteziyle olan uygunluğunu araştırır. Bulunan değerin 0,90 üzerinde olması gerekir ve 1'e ne kadar yaklaşırsa o kadar fazla uyum iyiliğine sahiptir (Ventura, 2011). Çalışmada bu değer NFI=0,92 bulunmuştur. RMR değeri 0'a yaklaştıkça test edilen modelin daha iyi uyum iyiliği gösterdiği anlaşılır (Ventura, 2011). Bu çalışmada RMR=0,09 bulunmuştur. SRMR değeri de 0'a yaklaştıkça modelin uyum iyiliği artar (Ventura, 2011). Bu çalışmada SRMR=0,074 bulunmuştur. CFI mevcut modelin uyumu ile gizil değişkenler arası korelasyonu ve kovaryansı 
yok sayan sıfır hipotez modelinin uyumunu karşılaştırır. CFI, 0-1 arası değişen değerler alır. 1'e yaklaştıkça uyum iyiliğinin arttığını gösterir veya daha yüksek CFI'ya sahip modelin daha güçlü uyum içinde olduğunu vurgular (Ventura, 2011). CFI=0,94 olarak bulunmuştur. AIC-Modeli ve ECVI karşılaştırma modelin AIC ve ECVI değerlerinden küçük olmalıdır (Erkorkmaz vd., 2013). $\mathrm{Bu}$ çalışmada AIC-Model 2478,59<24948,80 ve ECVI 3,39<63,48 bulunmuştur. Dolayısıyla modelin uyum iyiliği yeterlidir.

Tablo 4. Ölçüm Modeli İçin Uyum Ölçüleri

\begin{tabular}{|l|l|l|}
\hline Uyum Ölçüsü & Değer (İndeks) & Uyum \\
\hline $\mathbf{x}^{2} / \mathbf{d f}$ & 3,96 & Kabul Edilebilir \\
\hline RMSEA & 0,08 & Orta Uyum \\
\hline GFI & 0,91 & İyi Uyum \\
\hline NFI & 0,92 & Iyi Uyum \\
\hline RMR & 0,09 & Kabul Edilebilir \\
\hline SRMR & 0,074 & İyi Uyum \\
\hline CFI & 0,94 & İyi Uyum \\
\hline AIC-Model & $2478,59<24948,80$ & Iyi Uyum \\
\hline ECVI & $3,39<63,48$ & İyi Uyum \\
\hline
\end{tabular}

Katılımcıların ölçek ifadelerine olan algıları boyutlar kapsamında Tablo 5'de verilmiştir.

Tablo 5. Katılımciların İfadelere Algı Düzeyleri

\begin{tabular}{|c|c|c|}
\hline Katıldığım /Katılmayı tercih edeceğim açıkalan rerkreasyon aktivitelerinde, & 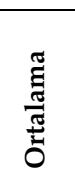 & $\dot{\omega}$ \\
\hline \multicolumn{3}{|l|}{ Başarı Odaklılık } \\
\hline ........yeni bir başarı elde edeceğim düşüncesi beni heyecanlandırır & 4,48 & 0,826 \\
\hline .........yaşadığım başarısızlıklar beni yıldırmaz & 4,09 & 1,010 \\
\hline ........zihnimi sürekli hedefimdeki işle meşgul ederim. & 3,92 & 1,078 \\
\hline ........işimimi şansa bırakmam. & 4,11 & 0,980 \\
\hline ........sürekli olarak yaptığımın daha iyisini nasıl başarabileceğime odaklanırım. & 4,10 & 0,973 \\
\hline ........başarısız olmamak için ekstra çaba harcarım. & 4,14 & 0,961 \\
\hline $\begin{array}{l}\text {.......engellerle karşılaştı̆ıımda bile başarı elde edeceğime inanmaya/ güvenmeye } \\
\text { devam ederim. }\end{array}$ & 4,21 & 0,959 \\
\hline ........her şeyi kusursuz yapmak isterim. & 4,05 & 1,042 \\
\hline ....başarılı olduğumun onaylanması benim için önemlidir. & 3,87 & 1,208 \\
\hline ...başarılı olduğumda hemen yeni hedefler oluşturmak isterim. & 3,98 & 1,160 \\
\hline \multicolumn{3}{|l|}{ Zorluklara Meydan Okuma } \\
\hline ........başarilı olduğumda hemen yeni hedefler oluşturmak isterim. & 3,85 & 1,116 \\
\hline ........yeteneklerimin üst sınırında olan zorlukları ararım & 4,22 & 0,934 \\
\hline ........karmaşık hedefleri başarmaktan zevk alırım & 4,05 & 0,967 \\
\hline .........kendime gerçekçi ama zorlu hedefler koyarım & 3,53 & 1,268 \\
\hline ........doğaya meydan okumayı severim & 3,77 & 1,152 \\
\hline ........zor etapları kolay olanlara tercih ederim & 4,01 & 1,102 \\
\hline ........güçlü ve dayanıklı olduğumu kanıtlamayı severim & 3,68 & 1,167 \\
\hline .........zor etaplar için yaratılmış bir birey olduğumu düşünüyorum & 3,88 & 1,097 \\
\hline ........zorluklara karşı dayanma kapasitemi yükseltecek aktiviteleri & 4,08 & 0,899 \\
\hline
\end{tabular}




\begin{tabular}{|c|c|c|}
\hline Risk Alma & & \\
\hline ........üstesinden geleceğim engeller olduğunda risk alırım & 4,06 & 0,986 \\
\hline ........zor etaplara beni çeken özelliklerden biri de riski sevmemdir. & 3,82 & 1,119 \\
\hline ........içimden bir duygu beni risk almaya iter. & 3,64 & 1,183 \\
\hline ........adrenalinimi yükselten deneyimler yaşamaktan hoşlanırım. & 4,05 & 1,102 \\
\hline ........riskli durumlar karşısında endişe seviyem düşüktür. & 3,56 & 1,222 \\
\hline ........rahatsız edici / tehdit edici durumlara meydan okumayı severim. & 3,62 & 1,227 \\
\hline \multicolumn{3}{|l|}{ Bireysellik } \\
\hline ........sorumlulukları paylaşmak yerine, kişisel sorumluluk almayı tercih ederim & 3,77 & 1,288 \\
\hline ........takım aktivitelerinden ziyade, bireysel olarak yapılan aktiviteleri tercih ederim & 3,52 & 1,294 \\
\hline ........diğgerlerinden daha hirslı ve daha iyi olmak beni motive eder. & 3,62 & 1,344 \\
\hline .......diğerlerinin benden daha iyi performans göstermesi beni olumsuz etkiler. & 3,07 & 1,468 \\
\hline $\begin{array}{l}\text {.......performansımı, iyi sonuç elde etmemden ziyade, diğerlerinden daha iyi olup } \\
\text { olmama durumumla değerlendiririm. }\end{array}$ & 3,17 & 1,456 \\
\hline \multicolumn{3}{|l|}{ Yenilik } \\
\hline ........amacım, yeni insanlarla tanışmaktır. & 4,26 & 0,971 \\
\hline ........başkalarını etkileyecek yeni fikirler sunarım. & 3,96 & 1,021 \\
\hline ........yeni şeyleri denemek bana haz verir, & 4,38 & 0,878 \\
\hline ........bir önceki seferden daha başarılı olmak için yeni taktikler uygularım. & 4,24 & 0,830 \\
\hline ........geliştirilen yeni uygulamaları merak ederim. & 4,05 & 0,977 \\
\hline .......diğerlerini de yeni fikirler üretmeleri için heveslendiririm. & 4,03 & 1,003 \\
\hline
\end{tabular}

Tablo 5 incelendiğinde katılımcıların algısının en yüksek olduğu ilk üç ifade yeni bir başarı elde edeceğimi düşünmek beni heyecanlandırıyor, yeni bir şeyler denemek bana haz veriyor ve yeni insanlarla tanışmayı amaçlıyorum ifadeleridir. katılımcıların algısının en yüksek olduğu üç ifade ise diğerlerinin benden daha iyi performans göstermesi beni olumsuz etkiliyor, performansımı aktivitenin sonunda iyi sonuç elde etmemden ziyade diğerlerinden daha iyi olup olmamla değerlendiriyorum, takım aktivitelerinden ziyade bireysel olarak yapılan aktiviteleri tercih ediyorum ifadeleridir. Genel olarak değerlendirildiğinde katılımcıların başarma ihtiyacı boyutlarından bireysellik boyutuna diğer boyutlara kıyasla daha düşük algı düzeyi bulunmaktadır.

\section{SONUÇ ve ÖNERILER}

Açık alan rekreasyon aktivitelerine katılmanın bazı riskleri bulunmaktadır.Riskler gerçekleştirilen açı alan rekreasyonu türüne göre değişmektedir; örneğin paraşütle atlama, yaparken insanlar yerçekimi kuvvetinden dolayı karıncalanma veya uyuşma hissiyle karşılaşabilir. Bu zorluk faktörlerine rağmen bireyler bu tür açık alan rekreasyon faaliyetlerine katılmaktadır. Bundan dolayı bireylerin açık alan rekreasyon faaliyetlerine katılmaları için nasıl motive oldukları ile ilgili bazı unsurlar belirlenmiştir: akış (Csikszentmihalyi, 1990); duyum arayışı (Zuckerman, 1994), öz yeterlik (Llewellyn ve Sanchez, 2008) ve içsel motivasyon (Asci vd., 2007; Deci ve Ryan, 2000). Bazı çalışmalar da açık alan rekreasyon aktivitelerine katılımın motivasyona bağlı olarak belirlenebileceğini ifade etmektedir (Schüler vd., 2014). Bu kapsamda çalışmanın temel amacı 'rekreasyon aktivitelerine katılım motivasyon ölçeği' geliştirmektir.

Literatür taraması sonucu madde havuzu oluşturulmuştur. Uzman görüşü sonrası hazırlanan anket formu Antalya destinasyonunda spor kulüplerine üye olan ve olmayan amatör rekreasyon katılımcılarına uygulanmıştır. Ölçek ile ilgili açımlayıcı ve doğrulayıcı analizler gerçekleştirilmiştir. Faktör analizi sonucuna göre, toplam varyansın \%60,86'sını açıklayan beş boyutlu (başarı odaklılık, zorluklara meydan okuma, risk alma, bireysellik ve yenilik) ölçek elde 
edilmiştir. CA değerleri ise, 0,80 üstüdür ve bundan dolayı boyutlar güvenilirdir ve iç tutarlığa sahiptir. Faktör analizi sonrasında yapısal eşitlik modeli aracılı̆̆ıyla DFA analizi yapılmıştır. Sonuçlara göre ölçüm modelinin uyum iyiliği yeterlidir.

Çalışma sadece Antalya destinasyonunda toplanan veriler ile gerçekleştirilmiştir. Geliştirilen ölçek ile farklı destinasyonlarda farklı gruplarla ve daha fazla katılımcı ile veriler toplanıp test edilmesi önemli olabilir. Benzer şekilde, çalışmada gerçekleştirilen ölçek ile farklı alanlardaki açık alan rekreasyon faaliyetlerine katılanlardan veri toplanarak ölçeğin test edilmesi ölçeğin genellenebilmesi için önerilmektedir.

\section{KAYNAKÇA}

Amabile, T. M., Hill, K. G., Hennessey, B. A. and Tighe, E. M. (1994). The Work Preference Inventory: Assessing Intrinsic and Extrinsic Motivational Orientations,Journal of Personality and Social Psychology, 66(5): 950-967.

Ardahan, F. and Lapa, Y. T. (2011). Outdoor Recreation: The Reasons and Carried Benefits for Attending Outdoor Sports of the Participants of Cycling and/or Trekking Activities,International Journal of Human Sciences,8(1):1327-1341.

Armutcu, F. (2018). Fiziksel Aktivite Amaçl Park ve Rekreasyon Alanlarının Kullanımını Etkileyen Faktörlerin Belirlenmesi, Yayınlanmamış Yüksek Lisans Tezi, Batman Üniversitesi, Batman.

Asci, F. H., Demirhan, G. and Dinc, S.C. (2007). Psychological Profile of Turkish Rock Climbers: An Examination of Climbing Experience and Route Difficulty,Perceptual and Motor Skills, 104(3):892-900.

Başarangil, İ. (2018). Akademisyenlerin Boş Zaman Aktivitelerine Katılımı, İş Tatmini ve İş Verimliliği: Kırklareli Üniversitesi'nde Bir Araştırma, Turizm Akademik Dergisi, 5(2): 155-170.

Berman, M. G., Jonides, J. and Kaplan, S. (2008). The Cognitive Benefits of Interacting With Nature, Psychological Science, 19(12):1207-1212.

Bipp, T. and Dam, K. (2014). Extending Hierarchical Achievement Motivation Models: The Role of Motivational Needs for Achievement Goals and Academic Performance,Personality and Individual Differences, 64:157-162.

Boyatzis, R. (2000). Whatif Learning werethePurpose of Education? DevelopingtheWholePersonandEmotionalIntelligence, LeadingEdge, Journal of theLondonLeadershipCentre, 4(2): 116-131.

Bozdoğan, A. E. ve Öztürk, Ç. (2008). Coğrafya ile İlişkili Fen Konularının Öğretimine Yönelik Öz-Yeterlilik İnanç Ölçeğinin Geliştirilmesi, Necatibey Eğitim Fakültesi Elektronik Fen ve Matematik Ĕ̈itimi Dergisi, 2(2): 66-81.

Bringhtbill, C. K. (1961). Man and Leisure: A Philosophy of Recreation. Englewood Cliffs: PrenticeHall.

Broadhurst, R. (2001). Managing Environments for Leisure and Recreation.New York: Routledge.

Chen, G., Gully, S. M., Whiteman, J. A. and Kilcullen, B. N. (2000). Examination of Relationships among Trait-Like Individual Differences, State-Like Individual Differences, and Learning Performance,Journal of AppliedPsychology,85(6):23-32.

Conroy, D. E., Elliot, A. J. and Hofer, S. M. (2003). A $2 \times 2$ Achievement Goals Questionnaire for Sport: Evidence for Factorial Invariance, Temporal Stability, and External Validity,Journal of Sport and Exercise Psychology, 25(4): 456-476. 
Csikszentmihalyi, M. (1990). Flow: The Psychology of Optimal Experience. New York: Harper and Row.

Daft, R. L. (2008). The Leadership Experience. (4th Edition),Mason, OH: Cengage Learning.

Deci, E. L. and Ryan, R. M. (2000). Intrinsic and Extrinsic Motivation: Classic Definitions and New Directions, Contemporary Educational Psychology, 25(1):54-67.

Demir, C. ve Demir, N. (2006). Bireylerin Boş Zaman Faaliyetlerine Katılmalarını Etkileyen Faktörler ile Cinsiyet Arasındaki İlişki: Lisans Öğrencilerine Yönelik Bir Uygulama,Ege Akademik Bakış Dergisi, 6(1): 36-48.

Douglas, M. K. (1980). Outdoor Recreation. New York: Macmillan Publishing Company.

Elliot, A. and Church, M. (1997). A Hierarchical Model of Approach and Avoidance Achievement Motivation, Journal of Personality and Social Psychology, 72(1):218-232.

Elliot, A. J. and Murayama, K. (2008). On the measurement of achievement goals: Critique, illustration, and application, Journal of Educational Psychology, 100(3): 613-628.

Emmons, R. A. (1997). Motives and Life Goals, (Editor) Briggs, S., Hogan, R. and Johnson, J. A.:Handbook of Personality Psychology in(p. 485-512) San Diego, CA: Academic Press.

Erkorkmaz, Ü., Etikan, İ., Demir, O., Özdamar, K. ve Sanisoğlu, S. Y. (2013). Doğrulayıcı Faktör Analizi ve Uyum İndeksleri,Türk Klinikleri Journal of Medical Sciences, 33(1): 210-223.

Hall, A. T., Royle, M. T., Brymer, R. A., Perrewe, P. L., Ferris, G. R. and Hochwarter, W. A. (2006). Relationships Between Felt Accountability As a Stressor and Strain Reactions: The Neutralizing Role af Autonomy Across Two Studies, Journal of Occupational Health Psychology, 11(1):87-99.

Henderson, M. C. (1995). Nurse Executives: Leadership Motivation and Leadership Effectiveness, Journal of Nursing Administration, 25(4): 45-51.

İbrahim, H. and Cordes, K.A., (2002). Outdoor Recreation, Enrichment For a Lifetime, Urbana IL: Sagamore Publishing.

Jubenville, A. (1976). Outdoor Recreation Planning, Philadelphia: W. B. Saunders.

Llewellyn, D. J. and Sanchez, X. (2008). Individual Differences and Risk Taking in Rock Climbing,Psychology of Sport and Exercise, 99(4):413-426.

Lussier, R. N. and Achua, C. F. (2007). Leadership: Theory Application, Skill Development(3rd Edition)Mason, $\mathrm{OH}$ : Thomson South-Western.

Mansuroğlu, S. ve Dağ, V. (2019). Peyzaj Mimarlı̆̆ı Bölümü Öğrencilerinin Dış Mekan Rekreasyon Eğilimleri: Akdeniz Üniversitesi Örneği, Iğdır Üniversitesi Fen Bilimleri Enstitüsü Dergisi, 9(3): 1692-1703.

McClelland, D. C. and Koestner, R. (1992). The Achievement Motive, (Editor) Smith, C.:Motivation and Personality: Handbook of Thematic Content Analysisin (p. 143-152)New York: Cambridge UniversityPress.

McClelland, D. C. (1961). The Achieving Society.Princeton, NJ: Van Nostrand Company.

McClelland, D. C. (1975). Power: The Inner Experience.New York: Irvington.

McClelland, D. C. (1985). Human Motivation.Glenview, IL: Scott, Foresman.

McClelland, D. C. (1987). Characteristics of SuccessfulEntrepreneurs,Journal of Creative Behavior, 21(3):219-233. 
McClelland, D. C., Koestner, R. and Weinberger, J. (1989). How do Self-attributed and Implicit Motives Differ?,Psychological Review,96(4): 690-702.

Nunnally, J. C. (1970). Introduction to Psychological Measurement. New York: McGraw-Hill Book Company.

Plummer, R. (2009).Outdoor Recreation. New York and London: Routledge.

Priest, S. and Gass, M. (1997). Effective Leadership in Adventure Programming.Champaign, IL: Human Kinetics.

Prochniak, P. (2014). Wilderness Novelty Seeking Scale, Perceptual and Motor Skills, 119(2): 571590.

Prochniak, P. (2016). Need for Achievement in Outdoor Recreation: Scale Construction and Validation,Journal of Psychology and Behavioral Science, 4(2): 142-151.

Robbins, S. P. (2003). Organizational Behavior (10th Edition)Englewood Cliffs: Prentice-Hall.

Schüler, J., Wegner, M. and Knechte, B. (2014). Implicit Motives and Basic Need Satisfaction in Extreme Endurance Sports, Journal of Sport and Exercise Psychology, 36(3): 293-302.

Singh, S. (2007). Conceptualizing Leisure, Recreation and Tourism from an Anthropological Perspective,Tourism Recreation Research, 32(2): 67-74.

Swenson, D. X. (2000). David McClelland's 3-Need TheoryAchievement, Affiliation, Power. [Online] http://faculty.css.edu/dswenson/web/lead/mcclelland.html>[Erişim Tarihi: 08.04.2020].

Şencan, H. (2005). Sosyal ve Davranışsal Ölçümlerde Güvenilirlik ve Geçerlilik. Ankara: Seçkin Yayıncilik.

Tavşancıl, E. (2010). Tutumların Ölçülmesi ve SPSS ile Veri Analizi. Ankara: Nobel Yayıncılık.

Torkildsen, G. (1999). Leisure and Recreation Management. London: E. and FN Spon.

Ventura, K. (2011). AMOS (Analysis of Moment Structures) ve Yapısal Eşitlik Modeli. [Online] http://web.deu.edu.tr/upk15/docs/seminerSunumlari/AMOS\%20(ANALYSIS\%20OF\%20MOME NT\%20STRUCTURES)\%20VE\%20YAPISAL\%20ESITLIK\%20MODELI-

YRD.\%20DOC.\%20DR.\%20KETI\%20VENTURA.pdf>[Erişim Tarihi: 27.11.2019].

Veroff, J. (1992). Power Motivation, (Editor) Smith, C. P., Atkinson,J. W., McClelland, D. C. and Verhoff, J.: Motivation and Personality: Handbook of Thematic Content Analysisin (p. 278-285), New York: Cambridge University Press.

Yamaguchi, I. (2003). The Relations among Individual Differences, Needs, and Equity Sensitivity,Journal of Managerial Psychology, 18(4):324-344.

Yayla, Ö. ve Çetiner H. (2019). Boş Zamanların Değerlendirilmesinde Etkili Olan Faktörlerin Boş Zaman Tatminine Etkisi, Turizm Akademik Dergisi, 6(1): 219-228.

Yazıcıoğlu, Y. ve Erdoğan, S. (2004). Spss: Uygulamalı Bilimsel Araştırma Yöntemleri, Ankara: Detay Yayıncilık.

Zeller, R. A. and Carmines, E. G. (1978). Statistical Analysis of Social Data, Chicago: Rand McNally College Publishing Company.

Zuckerman, M. (1994). Behavioral Expressions and Biosocial Bases of Sensation Seeking.Cambridge: Cambridge University Press. 